requiring the critical assessment of proposed systems of generation and distribution of electrical power took him in this later period to Egypt and to Argentina. $\mathrm{H}_{\Theta}$ enjoyed his travels immensely, making many friends abroad, taking great delight in trying exotic foods and in solving new problems of linguistic communication.

But, full as it was, his career as a professional engineer was only part of his public life. For many years he had pondered two fundamental problems, one philosophicalthe relation of 'mind' to 'matter', and one cosmologicalthe creation and evolution of the universe. His approaches to these problems, adumbrated in Science versus Materialism (1940), were developed with characteristic tenacity in later works. The philosophical problem was further discussed in Mind, Life and Body (1951) and in his Riddell Memorial Lectures on Facts and Faith: the Dual Nature of Reality (1955). He then returned to cosmology. By the ruthless application of Occam's Razor, which Kapp later elevated to 'The Principle of Minimum Assumption', he disposed of the 'big bang' and other contemporary theories of the origin of the universe and, in 1940, concluded that creation is continuous : matter is continuously being created at random throughout existing space and is continuously being destroyed at random throughout existing matter. Inferences from this hypothesis, including the idea that the continuous destruction of matter is the cause of gravitation and the prediction that lunar rock will be found to be micro-porous and mechanically weak, are worked out in Towards a Unified Cosmology (1959). This book, his final work, is about to be published in a German edition. Kapp was disappointed by the reception of his cosmological theories and regretted that he lacked the mathematical skill to exploit fully the implications of his physical insights.

He immensely enjoyed tackling new huge problems, technological or administrative, obscured by detail and complicated by conflicting interests or economic constraints. His invariable technique was, first, patiently to seek the relevant guiding principles and then, having established them, to apply the principles rigorously and without fear or favour; Kapp abhorred the ad hoc. $\mathrm{He}_{\mathrm{e}}$ also enjoyed writing, especially as a means of solving intellectual problems: successive drafts on a given thesis were for him a means of self-communication, each new draft being not merely a polishing but a significant development of its predecessor -a process which continued until a solution, usually of a problem much more fundamental than the one he began with, was obtained. His interest in writing, and his long experience of the inadequacies of the working papers on which his consultancy work depended, led him to establish a lectureship in the presentation of technical information at University College and to found a Group, of which he was the very active presidont for seventeen years, and, more recently, a Research and Education Trust, all concerned with aspects of scientific and technical writing. He also led the British Society for the Philosophy of Science to its present autonomy and founded the Occam Society.

He sorved on the governing bodies of Middlesex Hospital Medical School and of Northampton College of Advanced Technology where, as chairman of the academic council, he recently devoted much thought to the transition of the College to university status. His committee work, always thoroughly prepared, gave the improssion to those who shared any one committee with him that that particular committee had commanded his whole attention since the previous meoting. But at one time in the 1950's he was an active member, if not chairman, of fifty assorted committees.

Yet he found time also to enjoy the arts-the ballet, the theatre and music especially-and to publish occasional compositions for the piano.

He died of a heart attack, physically tired by the long illness and death of his wife, but in full possession and control of his formidable faculties to the last, and leaving, as his friends would have expected, all his affairs and papers in perfect order. A son and daughter, both married, survive him.

B. C. Brookes

\section{Prof. A. Fraenkel}

Prof. Adolf Abraham Halevi Fraenkel, emeritus professor of mathematics at the Hebrew University of Jerusalem, died on October 15, 1965, at the age of 74 , after a short illness.

Prof. Fraenkel was born in Munich in 1891, of an illustrious Jewish family. He studied mathematics at the Universities of Munich, Marburg, Berlin and Breslau. In 1922, he started teaching at the University of Marburg, later obtaining there the chair of the renowned German algebraist, Hensel. In 1928, he was called to the University of Kiel. Three years later, he received an invitation from Dr. Chaim Weizmann, who was to become the first president of the State of Israel, to join the recently ereated Hebrew University of Jerusalem. Having been an ardent Zionist since his youth, Fraenkel accepted this invitation and, alternating with Prof. Fekete, became chairman of the Mathematical Institute of the Hebrew University. It was mostly due to him that the Institute quickly achieved a world-wide reputation. Almost all the present professors there are his former students, while other students occupy important positions in other scientific institutions.

During the yoars 1938-40, Fraenkel served as rector of the Hebrew University. For many years, he headed its Institute of Adult Education, spending on it much time and fruitful effort. He was a member of the National Council of the Jewish community in (then) Palestine and was active in the establishment of the State of Israel in 1948. He became one of the founding members of the Israel Academy of Sciences and Humanities.

Fraenkel started as an algebraist and was one of the first to study the theory of abstract groups, thereby paving the way for the investigation of abstract algebraic structures in general. His main contribution, however, was in the field of abstract set theory, a contribution which is still very much alive and finds its external expression in the fact that one of the major axiom systems of set theory is known as ' $Z F$ ', the ZermeloFraenkel system. Zermelo was the first to publish, in 1908 , a workable axiom system for set theory in order to fortify the foundations of that discipline which had become shattered through the discovery of paradoxes at the turn of the century. Fraenkel, in 1921, just a few months before a similar accomplishment by the late Norwegian mathematician, Th. Skolem, was able to increase decisively the logical rigour in the formulation of one of the axioms, the so-called axiom of subsets (or Aussonderungsaxiom), and to add considerable strength to the system by the addition of another axiom, the axiom of replacement. As a result of the life-long interest in the axiom of choice, an interest which was of combined mathematical and philosophical origin, he made significant contributions towards the final proof of independency of this axiom, achieved only three years ago by P. J. Cohen and hailed as one of the major achievements of this century.

Fraenkel's philosophy of mathematics was an unabashed Platonism, and he stuck to this view even when it was no longer fashionable. But his deep eonvictions in this respect did not hinder him from becoming one of the main interpreters of intuitionism in his text-books, which have long since become classics in their fields.

Fraenkel was deeply religious but of extraordinary tolerance and liberalism towards his environmont. He combined his religious and mathematical interests in a thorough investigation of the Jewish calendar.

For many of his students Fraenkel was tho decisive factor in shaping their lives, and they will never forget this man who combined ice-cold scientific rigour with the warmest interest in their scientific and other progress, 
who applied the highest standards to himself and tried, successfully, to live up to them, but took the foibles of his environment smilingly in his stride.

Among Fraenkel's hobbies were mountaineering and swimming, both of which he pursued until his last days.
Having served during the First World War as a meteorologist with the German Army, he continued to remain interested in the field for the rest of his life.

Prof. Fraenkel is survived by his wife and four children. Y. BAR-HILleL

\section{NEWS AND VIEWS}

\section{Acceleration at the Rutherford}

THe $£ 11$ million $7 \cdot 2 \mathrm{GeV}$ proton synchrotron at the Rutherford High Energy Laboratory at Chilton, Berkshire, has at last begun to resemble the white elephant which is the Thai symbol of prosperity and good luck. Scarcely 10 months after Nimrod was opened in April, 1964, disintegration of the power supply motors caused a 10 -month halt for repairs that were only completed 5 months ago. Now the operation of the laboratory is only interrupted every 3 weeks when ultrasonic tests are made in order to assure the laboratory that the stable door at least is guarded.

In practice, Nimrod has been running for 80 per cent of the time allocated to experiments-60 per cent of the total clock time-the other 20 per cent being lost in periodic breakdowns lasting from $30 \mathrm{~min}$ to a few hours. At this rate, Dr. Thomas Pickavanco, the director of the laboratory, thinks it will be economic to run for another 15-20 years. Considering that the machine is in nearly continuous operation, Dr. Pickavance is pleased with the present level and, in fact, hopes within the year to equal the 90 per cent record at CERN - which, according to him, has had much longer breakdowns. Dr. Pickavance's colleagues, such as Dr. G. H. Strafford, head of the HighEnergy Physics Division, believe that brief interruptions do not affect most experiments, and that increased beam extraction and greater beam intensity would be more important improvements. On another scale the laboratory hopes soon to circumvent, by introducing portable units, the bottleneck caused when an experiment is dismantled. Already twice as many experiments have been submitted as there is floor space available; the waiting period is often one to two years, though much of this is profitably used for preparation. Twelve to fifteen university physies departments make regular use of Nimrod, though only Oxford, Cambridge, and London are convenient for commuting.

Pickavance believes that as larger machines are built small ones such as Nimrod will not be put out of business; there is still a great deal of work to do and a large number of machines will be needed to do it.

Nimrod's future role will depend largely on international plans; Pickavance mentioned that sites for a $300 \mathrm{GeV}$ European accelerator have been considered but nothing definito decided. The United States is planning a $200 \mathrm{GeV}$ accelerator for early in the $1970 \mathrm{~s}$; France and the U.S.S.R. have recently agreed to co-operate on the 70 GeV electron accelerator being built in Serpukhovo by the Russians.

\section{Electrostatic Generator at Oxford}

A TANDEM electrostatic machine for $20-\mathrm{MeV}$ protons in coupled operation has been installed in the Nuclear Physics Laboratory, University of Oxford. The system consists of a vertical injector-the pressure vessel of which is $42 \mathrm{ft}$. long and $13 \mathrm{ft}$. internal diameterdeveloped by the Electrostatic Generator Group of the Rutherford High Energy Laboratory, coupled to a horizontal 6-MeV (type E.N.) tandem, of which the generator was provided by High Voltage Engineering Europa of Amersfoort, Holland; the commissioning was carried out by the Oxford Electrostatic Generator Group. In single operation, the injector has delivered microampere beams of negative hydrogen ions at $10 \cdot 2 \mathrm{MeV}$, negative oxygen ions at $9.5 \mathrm{MeV}$ and $\mathrm{He}^{++}$at $15.6 \mathrm{MeV}$, corresponding to $9 \cdot 7 \mathrm{MoV}$ on the terminal.

In operation, when coupled with the tandem, protons of $20 \mathrm{MeV}$ energy have been delivered on target. The transmission efficiency has varied between 12 per cent and 30 per cent: this is illustrated in the case of hydrogen by 0.25 uamp analysed proton beam for $1.5 \mu \mathrm{amp}$ of hydrogen negative beam injected into the tandem, and for oxygen by 0.9 uamp of oxygen analysed in the $6+$ charge state for $1 \cdot 3$ mamp of negative oxygen injected.

\section{Earthquakes and Buildings}

THE book Earthquake Investigations in the Western United States, 1931-64, published by the U.S. Department of Commerce, Coast and Geodetic Survey (Publication 41-2), is a notable record of activity in the fields of earthquake recording and ongineering and seismology.

Some of the material was first published in 1936 (U.S.C.G.S. Special Publication 201), including papers by R. S. MeLean and W. W. Moore, R. R. Martel and the late Frank Neumann. New papers include several on instruments and instrumental studies and on damage studies.

The paper by John A. Blume on "The Building Vibrator" describes three vibrators at present in use, together with the methods of testing. In buildings, the vibrator is securely braced between two columns. A 4 in. $\times 4$ in. strut is placed horizontally between the end of the vibrator and the adjoining column and is screwed tightly into place by means of two large bolts attached to the frame of the machine, or by a jack. To steady the apparatus, ballast is usually placed on skids bolted to the base of the machine. On structures in which there are no columns or walls for bracing, it is necessary to resort to other methods of transmitting the disturbing forces. On the Colorado Strect Bridge, the vibrator was held in place mainly by piling a large number of sacks of cement on the skids. For ground shaking tests a heavy wooden framework was constructed to enclose a large vibrator. For horizontal forces, the frame may be jacked between curbs of a roadway, and it may be weighted down for vertical shaking. Rosulting vibrations in structures or in the ground are measured by portable seismographs. For buildings a magnification of about 200 may be used, but for dams or on the ground the magnifications may be 1,500 to 10,000 .

The tests have included buildings, dams, bridges, rock, and hard and soft ground. In each case, records showing forced vibration have been obtained. The test results indicate that such machines can be used to obtain valuable information that otherwise would be difficult to determine regarding the vibration characteristics of structures. This is especially true when simultaneous timing and recording are available from several sections of the structure. The use of the vibrator enables the positive identifieation of soveral of the highest natural periods of vibration in each translational direction of multi-storey buildings, and also the plotting of foreed vibration 